Gut, 1989, 30, 46-49

\title{
Abnormal cardiovascular reflexes in patients with gastro-oesophageal reflux
}

\author{
T K CHAKRABORTY, A L OGILVIE, R C HEADING, AND D J EWING \\ From the University Department of Medicine, Royal Infirmary, Edinburgh
}

SUMmary Using five non-invasive tests, abnormalities of cardiovascular reflex function were found in 20 of 50 patients with gastro-oesophageal reflux. Abnormalities of pupil cycle time, an index of non-vagal parasympathetic function, were found in only a few patients, implying that the cardiovascular abnormalities observed were not part of a generalised parasympathetic defect. The findings are consistent with the hypothesis that an abnormality of vagal function may contribute to the pathogenesis of gastro-oesophageal reflux.

\begin{abstract}
Although incompetence of the lower oesophageal sphincter is generally accepted as the principal cause of gastro-oesophageal reflux, the mechanisms responsible are still unclear. Normal sphincter function is mainly controlled through the vagus nerve. The sphincter response to raised intraabdominal pressure, which is mediated by a vagovagal reflex, is reduced in many patients with gastro-oesophageal reflux. ${ }^{2}$ Recently, however, the possibility that this is not just a simple consequence of sphincter failure has been raised by observations that patients with gastro-oesophageal reflux exhibit an impaired gastric secretory response to insulin (which depends on gastric vagal innervation $)^{23}$ and impairment of the heart rate response to deep breathing (which depends on cardiac vagal innervation). ${ }^{23} \mathrm{An}$ abnormality of vagal function may therefore be more prevalent among patients with gastro-oesophageal reflux than has hitherto been appreciated and could, in fact, contribute to the pathogenesis of the disorder.

Interpretation of a single test of cardiovascular reflex function is difficult. This study was therefore undertaken to amplify these previous observations using a wider range of cardiovascular autonomic function tests, together with measurement of pupil cycle time (a test of non-vagal parasympathetic function), in a group of patients with gastrooesophageal reflux.
\end{abstract}

Address for correspondence: Dr R C Heading, University Department of Medicine, Royal Infirmary, Edinburgh EH39YW.

Received for publication 15 July 1988

Reprints will not be available from the authors.

\section{Methods}

PATIENTS

Patients with gastro-oesophageal reflux were recruited from subjects referred with presumed oesophageal disease. The duration and severity of oesophageal symptoms (heartburn, pain on swallowing and regurgitation) was recorded and symptoms graded as mild, moderate or severe (scored 1,2, or 3 ), and a total 'symptom score' of 0-9 derived. All subjects underwent endoscopy and oesophageal biopsy, and the degree of endoscopic oesophagitis graded according to a previously defined schedule. ${ }^{4}$ The oesophageal biopsies were scored as positive or negative according to the presence or absence of oesophagitis.

\section{OESOPHAGEAL STUDIES}

Oesophageal motility was measured in all patients using a multiple lumen tube perfused by a hydraulic infusion system. The lower oesophageal sphincter pressure was estimated by the rapid pull through technique and the amplitude and duration of peristalsis in the lower oesophagus measured from the last five of 15 swallowed boluses of $5 \mathrm{ml}$ water given at 20-30 second intervals. ${ }^{5}$

Ambulatory intraoesophageal $\mathrm{pH}$ monitoring was undertaken for a period of 23 hours as described previously. ${ }^{6}$ The recordings were analysed for the percentage of time during which intraoesophageal $\mathrm{pH}$ was less than 4 , the number of reflux episodes which occurred, and the average clearance time in seconds for each reflux episode. These measure- 
ments were computed separately for the total and sleeping periods.

Fifty patients ( 26 men, 24 women), mean age 52 (range 15-75) years, were selected on the basis of intraoesophageal $\mathrm{pH}$ measurements showing a $\mathrm{pH}$ of less than 4 for more than $10 \%$ of the recording time. None had symptoms of autonomic neuropathy, none was diabetic and none had other upper gastrointestinal pathology or previous upper abdominal surgery. No patients were on beta-adrenergic or cholinergic blocking drugs at the time of the study. Forty nine of the 50 patients had normal oesophageal motility patterns to wet swallows; the remaining patient showed some non-propulsive contractions after swallowing. These were not sufficiently frequent to justify a diagnosis of oesophageal spasm.

\section{AUTONOMIC STUDIES}

All patients were submitted to a battery of five standard cardiovascular autonomic reflex tests which have been widely used, particularly in assessing diabetic autonomic neuropathy. These comprised the heart rate responses to the Valsalva manoeuvre, deep breathing and standing up, and the blood pressure responses to standing up and to sustained handgrip. The tests have been described in detail previously, and the normal, borderline and abnormal ranges used are based on our results from nearly two hundred normal subjects. ${ }^{78}$ A score of 0,1 , or 2 was assigned to each test depending whether the result was normal, borderline or abnormal, giving a total 'autonomic score' ranging from 0 - 10 for each subject. For the purposes of this study, a score of 3 or more was taken to indicate definite autonomic damage. This meant that two or more different tests showed abnormality, and that definite autonomic involvement was present in these subjects.

Thirty seven patients had 24 hour ambulatory heart rate recordings during their normal daily activities. The remaining 13 subjects either did not wish to have ambulatory monitoring, or the recordings were technically unsatisfactory. We have previously described a technique using the 24 hour tape recordings, to assess cardiac parasympathetic function by measuring beat by beat heart rate changes over the 24 hours and deriving a 'count' of heart rate changes for each individual. Values of under 1000 are probably abnormal.

In addition, the pupil cycle time was assessed in each subject. If a slit of light is directed on the pupil, a cycle of contraction and dilatation can normally be induced and can easily be timed. The longer pupil cycle time of the two eyes was used in the results. The normal response is predominantly dependent on an intact parasympathetic efferent pathway to the pupil and abnormal responses correlate well with cardio-
Table 1 Results of cardiovascular reflex tests in 50 patients with gastro-oesophageal reflux

\begin{tabular}{llll}
\hline & \multicolumn{3}{l}{ Number of patients } \\
\cline { 2 - 4 } Test & Normal & Borderline & Abnormal \\
\hline $\begin{array}{l}\text { Valsalva ratio } \\
\text { Heart rate variation with deep } \\
\text { breathing }\end{array}$ & 39 & 9 & 11 \\
30: 15 ratio & 45 & 4 & 19 \\
Response to standing & 35 & 12 & 3 \\
Response to sustained handgrip & 38 & 4 & 7 \\
\hline
\end{tabular}

vascular reflex abnormalities in diabetics. ${ }^{\text {"I }}$ Measurement of the pupil cycle time thus constitutes a test of non-vagal parasympathetic function.

STATISTICAL ANALYSIS

Student's unpaired $t$ test, $\chi^{2}$, trend test, and Wilcoxon's rank-sum tests were used as appropriate to assess statistical significance. The results are expressed as mean (SD) or median and range as appropriate.

\section{Results}

The results of cardiovascular autonomic reflex testing in the 50 patients with gastro-oesophageal reflux are shown in Table 1. Abnormalities of cardiovascular reflexes were common, with $38 \%$ of patients having an abnormal heart rate response to deep breathing and $22 \%$ an abnormal response to the Valsalva maneouvre. Three patients had abnormally large systolic blood pressure falls on standing. Twenty patients $(40 \%)$ had an autonomic score of 3 or more.

Table 2 Comparison of clinical features between patients with reflux and autonomic abnormalities and those without

\begin{tabular}{|c|c|c|c|}
\hline & \multicolumn{2}{|l|}{ ANS score } & \multirow[b]{2}{*}{ Significance } \\
\hline & $0-2$ & $3-7$ & \\
\hline Patients (n) & 30 & 20 & \\
\hline Mean age (years) & $46[16-68]$ & $61[41-76]$ & $\mathrm{p}<0) \cdot(0) 1$ \\
\hline $\operatorname{Sex}(M: F)$ & $20: 10$ & $6: 14$ & $p=0 \cdot(02$ \\
\hline Body mass index $\left(\mathrm{kg} / \mathrm{m}^{2}\right)$ & $25 \cdot 3 \pm 2 \cdot 7$ & $25 \cdot 4 \pm 2 \cdot 6$ & NS \\
\hline Smokers (n) & 7 & 3 & \\
\hline $\begin{array}{l}\text { Mean alcohol consumption } \\
\text { (units/week) }\end{array}$ & $5 \cdot 4[0-30]$ & $4[0-30]$ & NS \\
\hline $\begin{array}{l}\text { Duration of symptoms } \\
\text { (months) }\end{array}$ & $100[12-240]$ & $76[6-240]$ & NS \\
\hline \multicolumn{4}{|l|}{ Symptom score } \\
\hline Heartburn & $1 \cdot 8(0 \cdot 8)$ & $1 \cdot 7(0 \cdot 9)$ & NS \\
\hline Pain on swallowing & $0.4(0.7)$ & $0.5(0 \cdot 6)$ & NS \\
\hline Regurgitation & $0.9(0.9)$ & $1 \cdot 0(0 \cdot 8)$ & NS \\
\hline Total score & $3 \cdot 1(1 \cdot 6)$ & $3 \cdot 1(1 \cdot 9)$ & NS \\
\hline
\end{tabular}

Mean (SD); range []. 
Table 3 Comparison of results of laboratory investigations between patients with reflux and autonomic abnormalities and those without

\begin{tabular}{|c|c|c|c|}
\hline & \multicolumn{2}{|l|}{ ANS score } & \multirow[b]{2}{*}{ Significance } \\
\hline & $0-2$ & $3-7$ & \\
\hline Patients (n) & 30 & 20 & \multirow{4}{*}{$\begin{array}{l}\chi^{2} \text { trend }=4 \cdot 24 \\
p=0 \cdot(04\end{array}$} \\
\hline \multirow{3}{*}{$\begin{array}{l}\text { Endoscopic } \\
\text { oesophagitis } \\
\text { (pts) }\end{array}$} & 15 & 5 & \\
\hline & 9 & 5 & \\
\hline & 6 & 10 & \\
\hline \multirow{2}{*}{$\begin{array}{l}\text { Biopsy score } \\
\text { (pts) }\end{array}$} & 17 & 13 & \multirow{2}{*}{$\begin{array}{l}\chi^{2}=2 \cdot 34 \\
\text { NS }\end{array}$} \\
\hline & 13 & 7 & \\
\hline $\begin{array}{l}\text { Lower oesophageal } \\
\text { sphincter pressure } \\
(\mathrm{mmHg})\end{array}$ & $\begin{array}{l}24 \cdot 0 \\
{[8 \cdot 9-61 \cdot 6]}\end{array}$ & $\begin{array}{l}19 \cdot 3 \\
{[10 \cdot 6-94 \cdot 5]}\end{array}$ & NS* \\
\hline \multirow{2}{*}{$\begin{array}{l}\text { Peristaltic amplitude } \\
(\mathrm{mmHg}) \\
\text { Duration of peristaltic } \\
\text { wave (secs) }\end{array}$} & $\begin{array}{l}74 \cdot 6 \\
{[25-181]}\end{array}$ & $\begin{array}{l}76 \cdot 4 \\
{[10-165]}\end{array}$ & NS* \\
\hline & $3 \cdot 8(1 \cdot 1)$ & $3 \cdot 8(1 \cdot 1)$ & NS ${ }^{\dagger}$ \\
\hline \multicolumn{4}{|l|}{ Total reflux } \\
\hline$\%$ of time $\mathrm{pH}<4$ & $\begin{array}{l}14 \cdot 5 \\
{[10 \cdot 0-36 \cdot 9]}\end{array}$ & $\begin{array}{l}15 \cdot 3 \\
{[10 \cdot 2-31 \cdot 0]}\end{array}$ & NS* \\
\hline Clearance $(\min )$ & $\begin{array}{l}2 \cdot 85 \\
{[0 \cdot 8-22 \cdot 2]}\end{array}$ & $\begin{array}{l}3 \cdot 1 \\
{[0 \cdot 7-9 \cdot 6]}\end{array}$ & NS* \\
\hline \multicolumn{4}{|l|}{ Nocturnal reflux } \\
\hline$\%$ of time $\mathrm{pH}<4$ & $\begin{array}{c}9 \cdot 4 \\
{[0-64 \cdot 2]}\end{array}$ & $\begin{array}{l}15 \cdot 9 \\
{[0-37 \cdot 4]}\end{array}$ & NS* \\
\hline Clearance $(\min )$ & $\begin{array}{l}4 \cdot 3 \\
{[0-173 \cdot 5]}\end{array}$ & $\begin{array}{c}6 \cdot 3 \\
{[0-160]}\end{array}$ & NS* \\
\hline
\end{tabular}

*Wilcoxon's two sample rank-sum test; †Unpaired $t$ test; Mean (SD) or Median and range [] as appropriate.

They were compared with the remaining 30 subjects with scores of 0-2 (Tables 2 and 3). No differences were observed between the two groups with regard to clinical features, oesophageal manometric findings, or the magnitude of the gastro-oesophageal reflux, but the patients with definite evidence of autonomic abnormalities were older and had endoscopic evidence of more severe oesophagitis.

The mean resting and 24 hour waking and sleeping heart rates were higher in those subjects with larger autonomic scores (Table 4). Twelve of the 37 subjects $(32 \%)$ had 24 hour heart rate counts that were probably abnormal with values of less than 1000 .

Table 4 Resting and mean heart rates in patients with and without evidence of cardiovascular autonomic neuropathy

\begin{tabular}{llllllll}
\hline & \multicolumn{3}{l}{$\begin{array}{l}\text { Resting heart rates } \\
\text { (beats/min) }\end{array}$} & & \multicolumn{2}{l}{$\begin{array}{l}\text { Mean heart rate } \\
\text { (beats/min) }\end{array}$} \\
\cline { 2 - 4 } ANS score & Lying & Sitting & Standing & & Wake & Sleep \\
\hline $0-2(\mathrm{n}=30)$ & $67(8)$ & $73(11)$ & $77(12)$ & $(\mathrm{n}=21)$ & $77(13)$ & $61(11)$ \\
$3-7(\mathrm{n}=20)$ & $76(14)$ & $82(17)$ & $85(16)$ & $(\mathrm{n}=16)$ & $85(13)$ & $67(8)$ \\
Significance & $\mathrm{p}<0.02$ & $\mathrm{p}<0.05$ & NS & & NS & NS \\
\hline
\end{tabular}

Mean (SD).
No cycling
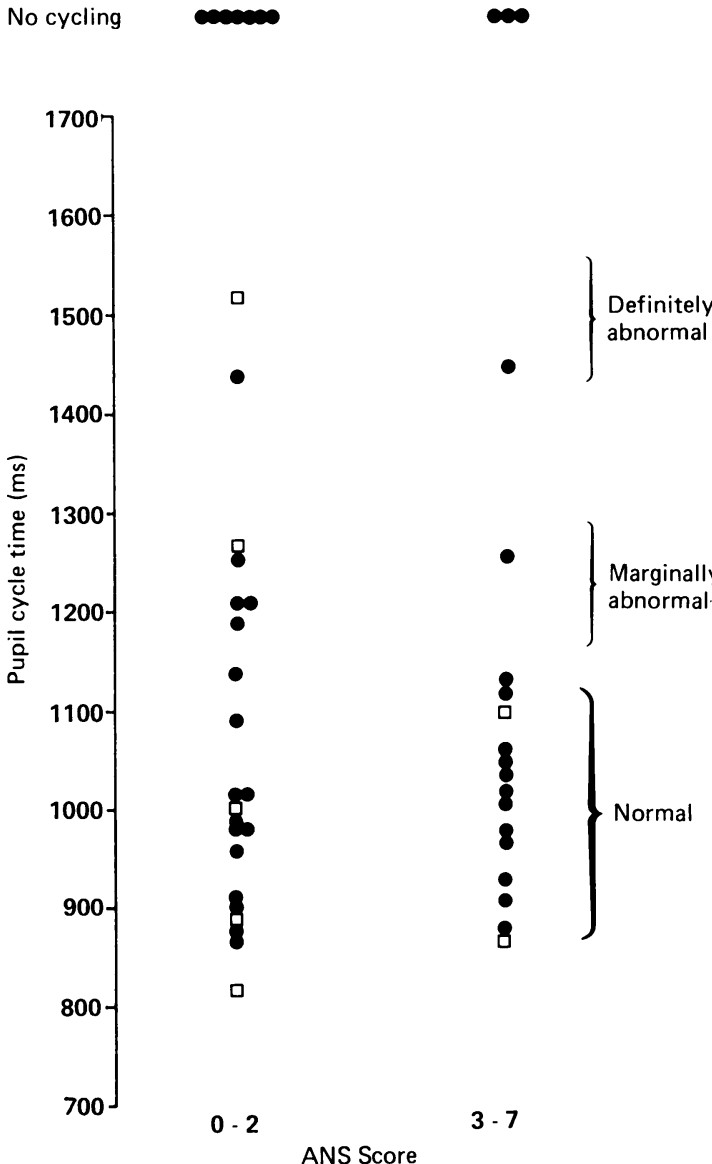

Figure Pupil cycle time in 50 subjects with gastrooesophageal reflux, divided according to their autonomic score $(\mathbf{O}=$ both eyes assessed, $\square=$ cycling induced in only one eye).

There was a significant correlation between the 24 hour 'counts' and the autonomic score derived from the cardiovascular reflex tests in the group of 37 subjects $(r=-0.407, p<0.02)$. Pupil cycle times are shown in the Figure. It was not possible to induce pupil cycling in 10 patients but was slightly greater than our previously defined upper limit of normal" in six subjects and more definitely prolonged in three of those in whom cycling was induced.

\section{Discussion}

Our results amplify previous reports of abnormal cardiovascular reflexes in patients with gastrooesophageal reflux which based their conclusions on a single cardiovascular reflex test, namely the heart rate response to deep breathing. Abnormality in those studies was identified in $44 \%^{3}$ and $29 \%$ of 
patients, ${ }^{2}$ which is comparable with the $38 \%$ in our study. The assumption that abnormalities of autonomic function can be confidently identified using only a single test of autonomic function is suspect, however, and a battery of tests is always to be preferred. Our battery of tests revealed unequivocal evidence of autonomic nervous system dysfunction in $40 \%$ of patients, although none had symptoms of autonomic failure. Although our patients with autonomic dysfunction were significantly older than those with normal cardiovascular reflexes, this is not simply an effect of age on autonomic function. We have previously published results from nearly 200 normal subjects ${ }^{\mathrm{x}}$ with a wide age scatter, and although there is a small diminution in the heart rate responses with age, results designated 'abnormal' in the present study are outside our normal range for subjects of any age.

The relative proportion of parasympathetic and sympathetic modulation varies with each cardiovascular response. ${ }^{*}$ Vagal parasympathetic pathways are predominant in the heart rate tests and play a small part in the blood pressure response to standing. There is little, if any, vagal involvement in the blood pressure response to sustained handgrip. Sympathetic pathways play a major part in the blood pressure responses and a minor role in the Valsalva and lying to standing responses. The predominant abnormality in our patients was in the heart rate tests, and therefore in cardiac vagal pathways. Had there been a generalised parasympathetic abnormality, pupil cycle time might have been expected to be more frequently abnormal, particularly in the group of patients with higher cardiovascular autonomic scores. This was not the case, indicating that the autonomic dysfunction was probably not generalised.

These cardiovascular reflex abnormalities are unlikely to be caused by reflux oesophagitis. In contrast with the two previous investigations, not all patients in our study had oesophagitis, as the basis of inclusion was abnormal gastro-oesophageal reflux on intra-luminal $\mathrm{pH}$ monitoring. Despite this, the incidence of cardiovascular reflex abnormalities appears similar in all three reports. Furthermore, cardiac vagal fibres leave the vagal trunk at a much higher level than seems compatible with frequent damage resulting from gastro-oesophageal reflux disease.

The existence of abnormal vagal function in $40 \%$ of our patients raises the possibility that vagal dysfunction is important in the genesis of gastrooesophageal reflux. Cardiovascular reflex tests act as markers for damage in other vagal fibres, including those controlling the lower oesophageal sphincter, gastric secretion and gastric emptying, where abnor- malities have been found in patients with gastrooesophageal reflux." We have recently found transpyloric fluid movement to be abnormal in patients with gastro-oesophageal reflux, with a pattern consistent with impaired vagal innervation. ${ }^{12}$ In another recent study, of irritable bowel syndrome, which may be associated with gastro-oesophageal reflux, abnormal vagal function was also demonstrated. ${ }^{13}$ Our findings support the hypothesis that in many patients with gastro-oesophageal reflux, the primary and causal defect of the disorder may lie within the vagus nerve.

Dr D J Ewing is a Wellcome Trust Senior Lecturer.

\section{References}

1 Ogilvic AL, Atkinson M. Influence of the vagus nerve upon the reflex control of the lower oesophageal sphincter. Gut 1984; 25: 253-8.

2 Ogilvie AL, James PD, Atkinson M. Impairment of vagal function in reflux oesophagitis. $Q J$ Med 1985; 54: $61-74$.

3 Heatley RV, Collins RJ, James PD, Atkinson M. Vagal function in relation to gastro-oesophageal reflux and associated motility changes. $\mathrm{Br} \mathrm{Med} J$ 1980; 280: 75.5-7.

4 DeMeester TR, Wang C-I, Wernly JA, et al. Techniques, indications and clinical use of 24 hour oesophageal pH monitoring. J Thorac Cardiovasc Surg 1980; 79: 656-70.

5 Dodds WJ, Hogan WJ, Stef JJ, Miller WN, Lydon SB, Arndorfer RC. A rapid pull through technique for measuring lower esophageal sphincter pressure. Gastroenterology 1975; 68: 437-43.

6 De Caestecker JS, Blackwell JN, Brown J, Heading RC. The oesophagus as a cause of recurrent chest pain: which patients should be investigated and which tests should be used. Lancet 1985; ii: 1143-6.

7 Ewing DJ, Clarke BF. Diagnosis and management of diabetic autonomic neuropathy. $B r$ Med $J$ 1982; 285: 916-8.

8 Ewing DJ, Martyn $\mathrm{CN}$, Young RJ, Clarke BF. The value of cardiovascular autonomic function tests: 10 years experience in diabetes. Diabetes Care 1985; 8: 491-8.

9 Ewing DJ, Neilson JMM, Travis P. New method for assessing cardiac parasympathetic activity using 24 hour electrocardiograms. Br Heart J 1984; 52: 396-402

10 Martyn CN, Ewing DJ. Pupil cycle time: a simple way of measuring an autonomic refiex. J Neurol Neurosurg Psychiatry 1986; 49: 771-4.

11 McCallum RW, Berkowitz DM, Lerner E. Gastric emptying in patients with gastroesophageal reflux. Gastroenterology 1981; 80: 285-91.

12 King PM, Pryde A, Heading RC. Transpyloric fluid movement and antroduodenal motility in patients with gastrocsophageal reflux. Gut 1987; 28: 545-8.

13 Smart HL, Atkinson M. Abnormal vagal function in irritable bowel syndrome. Lancet 1987; ii: 475-8. 